\title{
Development of a Management Algorithm for Acute and Chronic Radiation Urethritis and Cystitis
}

\author{
Ben G.L. Vanneste ${ }^{a} \quad$ Evert J. Van Limbergen ${ }^{a}$ Tom A. Marcelissen ${ }^{b}$ \\ Joep G.H. van Roermund ${ }^{b}$ Ludy C. Lutgens ${ }^{a}$ Carsten W.K.P. Arnoldussen ${ }^{c}$ \\ Philippe Lambind ${ }^{d}$ Matthias Oelke \\ aDepartment of Radiation Oncology (MAASTRO clinic), GROW, School for Oncology and Developmental Biology, \\ Maastricht University Medical Center, Maastricht, The Netherlands; ${ }^{b}$ Department of Urology, Maastricht University \\ Medical Centre, Maastricht, The Netherlands; 'Department of Radiology and Nuclear Medicine, VieCuri Medical Centre, \\ Venlo, The Netherlands; ${ }^{\mathrm{d} T h e}$ D-Lab, GROW, School for Oncology and Developmental Biology, Maastricht University \\ Medical Centre, Maastricht, The Netherlands; 'Department of Urology, St. Antonius Hospital, Gronau, Germany
}

\section{Keywords}

Radiotherapy - Radiation urethritis - Radiation cystitis ·

Prevention - Treatment

\begin{abstract}
Objective: The purpose of this review was to summarize the current literature on the assessment and treatment of radiation urethritis and cystitis (RUC) for the development of an evidenced-based management algorithm. Material and Methods: The PubMed/MEDLINE database was searched by a multidisciplinary group of experts in January 2021. Results: In total, 48 publications were identified. Three different types of RUC can be observed in clinical practice: inflammation-predominant, bleeding-predominant, and the combination of inflammation- and bleeding-RUC. There is no consensus on the optimal treatment of RUC. Inflammation-predominant RUC should be treated symptomatically based on the existence of bothersome storage or voiding lower urinary tract symptom as well as on pain. When bleeding-predominant RUC has occurred, hydration and hyperbaric oxygen therapy (HOT) should be used first and, if HOT is not available, oral drugs instead (sodium pentosane polysulfate,
\end{abstract}

karger@karger.com www.karger.com/uin

Karger $\stackrel{\text { ' }}{5}$

GOPEN ACCESS
(C) 2021 The Author(s)

Published by S. Karger AG, Basel

This is an Open Access article licensed under the Creative Commons Attribution-NonCommercial-4.0 International License (CC BY-NC) (http://www.karger.com/Services/OpenAccessLicense), applicable to the online version of the article only. Usage and distribution for commercial purposes requires written permission. aminocaproic acid, immunokine WF 10, conjugated estrogene, or pentoxifylline + vitamin E). If local bleeding persists, focal therapy of bleeding vessels with a laser or electrocoagulation is indicated. In case of generalized bleeding, intravesical installation should be initiated (formalin, aluminium salts, and hyaluronic acid/chondroitin). Vessel embolization is a less invasive treatment with potentially less complications and good clinical outcomes. Open- or robot-assisted surgery is indicated in patients with permanent, life-threatening bleeding, or fistulae. Conclusions: Treatment of RUC, if not self-limiting, should be done according to the type of RUC and in a stepwise approach. Conservative/medical treatment (oral and topic agents) should primarily be used before invasive (transurethral) treatments.

$$
\begin{aligned}
& \text { () } 2021 \text { The Author(s) } \\
& \text { Published by S. Karger AG, Basel }
\end{aligned}
$$

\section{Introduction}

Radiotherapy (RT) of the pelvis is a frequently used treatment option for the management of urological, gynecological, and gastrointestinal malignancies. RT techniques have improved during the last decades by using 
Fig. 1. Flowchart of studies, which were identified by the literature search, screened excluded or included from analysis.

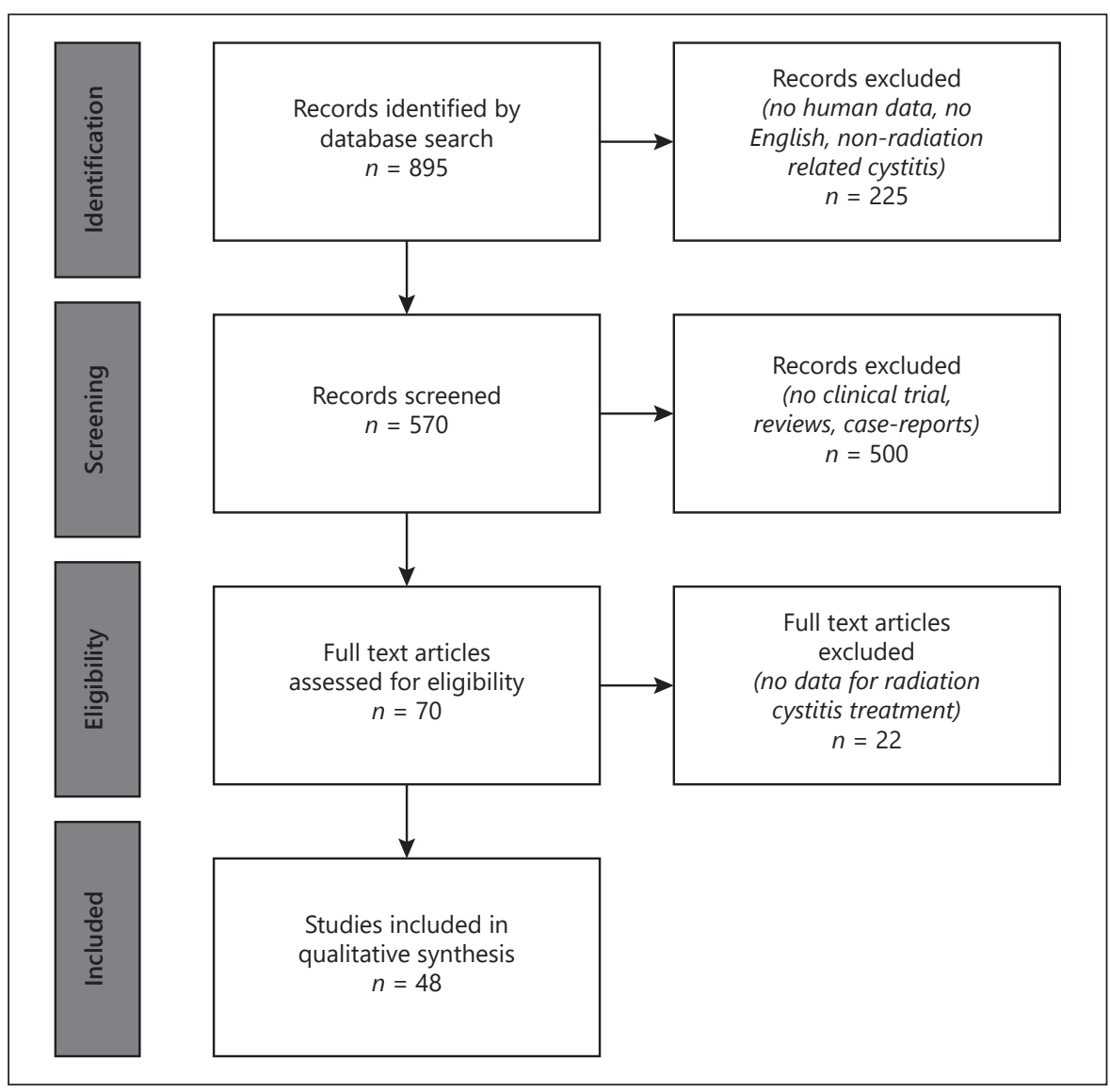

image-guided or intensity-modulated RT with decreasing side effects. Nevertheless, RT can still affect the adjacent healthy genitourinary tissues and gastrointestinal tract, thereby causing irritation and inflammation of the urethra, bladder, and rectum resulting in radiation urethritis, cystitis, and proctitis as well as decreasing the quality of life of patients [1]. Acute side effects occur by definition $\leq 3$ months after RT and are usually transient by symptomatic treatment as frequently applied in daily practice. Acute radiation urethritis and cystitis (ARUC) are very common with a reported incidence of up to $50 \%$ of irradiated patients [2]. Chronic radiation urethritis and cystitis (CRUC) appears by definition $>3$ months after RT with a clinical event-free interval ranging from a few months to many years [3]. Severe CRUC is less common and affects $5-10 \%$ of irradiated patients [2]. The probability of developing tissue injury is mainly related to the total radiation dose, RT technique, and the dose per fraction. Higher incidences are observed with doses $>50$ 60 Gray and after using conventional techniques versus intensity-modulated RT [2]. Individual patient factors may also influence the incidence of RUC, such as vascular or connective tissue diseases, diabetes mellitus, previous surgery (e.g., transurethral resection of the prostate or bladder), smoking, and concomitant chemotherapy [4]. Men are not more likely to develop a RUC than women. However, a higher ratio is observed of 2.8 versus 1 . This is mainly depended to the high proportion of prostate cancer RT use in the pelvic treatments [5].

Until now, the optimal management of RUC has not been defined. The aim of this article is to present a practical algorithm for the treatment of the whole spectrum of symptoms of ARUC and CRUC based on a literature review. The authors anticipate that the recommendations and algorithm will improve the management of RUC and help to define the best time for seeking specialist advice.

\section{Material and Methods}

This narrative review was written by a multidisciplinary group of experts on pelvic oncology, urologists, radiation oncologists, and clinical researchers and is based on a literature search in the PubMed/MEDLINE database in January 2021. Search terms included "radiation + cystitis" AND “+ treatment." Results were lim- 
Table 1. Radiation cystitis according to the "common toxicity criteria," version $4.0[6,7]$

\begin{tabular}{ll}
\hline RUC grade & Symptoms \\
\hline 1 & Urethral or bladder discomfort $\rightarrow$ intervention not indicated \\
\hline 2 & Symptomatic $\rightarrow$ medical intervention indicated (urinary catheter or bladder irrigation); limiting normal ADL \\
\hline 3 & Severe symptoms $\rightarrow$ gross hematuria; transfusion needed, hospitalization indicated; limiting self-care ADL \\
\hline 5 & Life-threatening consequences $\rightarrow$ urgent intervention indicated \\
\hline
\end{tabular}

ADL, activities of daily living.

Fig. 2. Cystoscopic features illustrating an atrophic bladder mucosa with telangiectasia, and spontaneous bleeding. The irradiated bladder mucosa is often atrophic with congested mucosae, telangiectasia, ulceration, stricture, necrosis, or spontaneous bleeding. Additionally and not shown on the photo, the patient had distal ureteral stenoses due to fibrosis.

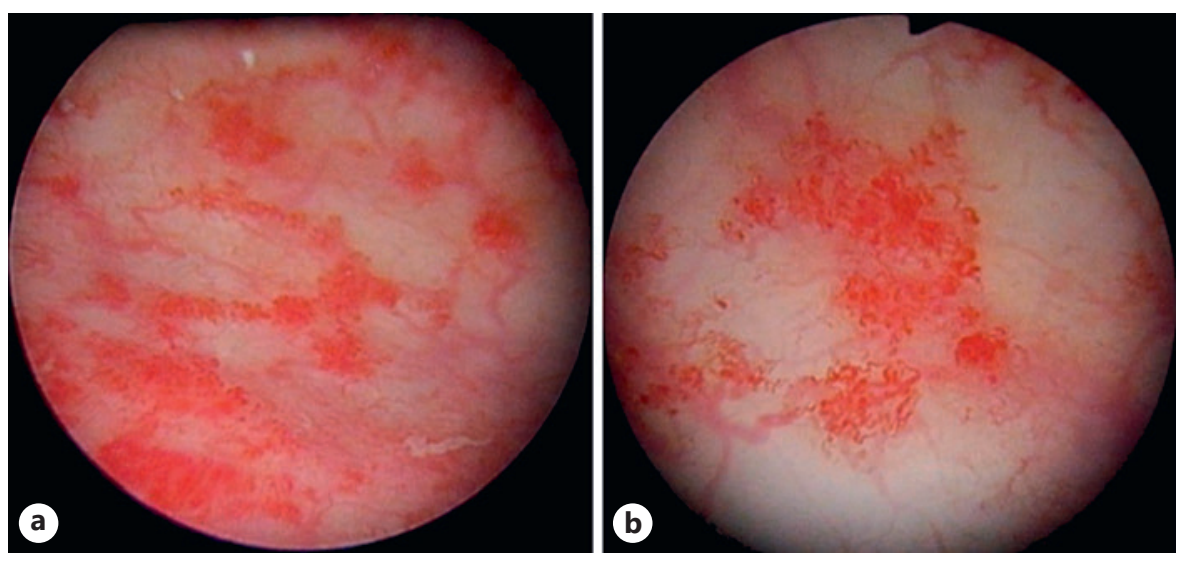

ited to the English language and humans. Trials without specific information on radiation cystitis were excluded (Fig. 1). A manual review of hits was conducted for relevance. In total, 48 publications were identified and included in this review. All recommendations are based on the best available evidence and combined with the individual expert authors' experiences in managing ARUC and CRUC.

\section{Results}

\section{Symptoms of RUC}

RT can cause both early (ARUC) and late (CRUC) side effects [3]. Late toxicities may also occur as a consequential effect of recurrent severe acute injury, as a consequence of acute injury resulting in "scars" with late effects [3]. RT side effects are categorized in 5 grades (Table 1), according to the National Cancer Institute Common Terminology Criteria for Adverse Events [6].

Genitourinary ARUC includes dysuria, urgency (urinary incontinence), pollakisuria, nocturia, low voided volumes, hematuria, or even urinary retention. Suprapubic discomfort or pain is common and often experienced as projected pain into the penis or vaginal aperture. Similar symptoms can be observed in patients with CRUC. In contrast to ARUC, hematuria is the most common symptom of CRUC, often associated with iron-deficiency anemia requiring blood transfusions or surgery with a perioperative mortality of approximately $4 \%$ [2]. In addition, patients may have symptoms of urinary retention due to urethral or bladder neck strictures or secondary to obstructing blood clots. Bladder wall fibrosis may lead to reduced bladder capacity, detrusor low compliance, urgency, or overflow urinary incontinence.

\section{Diagnosis of RUC}

Diagnosis is mainly made by symptoms and as exclusion of other potential conditions with similar signs, such as urinary tract infection, other malignancies, bladder outlet obstruction, or ureteral, bladder, or urethral stones [8]. CRUC can be suspected in patients who had pelvic RT and have abovementioned symptoms, even if RT was applied years or even decades before. However, caution should be made that several symptoms (like dysuria, urgency, and nocturia) are very frequently occurred symp- 
toms in older men even without RT. Assessment includes urinalysis, urine culture, and urine cytology to exclude urothelial carcinoma.

However, urinalysis and urine culture is only recommended when initial therapy with alpha-blockers is not successful in acute RUC to exclude secondary bacterial infection. The urine cytology to exclude urothelial carcinoma is only recommended to perform in chronic symptoms. Moreover, urine cytology should cautiously be interpreted because of cell changes due to RT. Bladder outlet obstruction can be estimated by several noninvasive parameters, such as uroflowmetry and measurement of post-void residual [9].

Further evaluation includes urethro-cystoscopy as well as examination of the lower and upper urinary tract by ultrasound, CT, or MRI to exclude other causes of hematuria. Urethro-cystoscopy is important to visualize telangiectasia and bleeding vessels (Fig. 2), exclude other malignancies, and determine the extent and severity of CRUC. Similar to chronic radiation proctitis, 3 main forms of endoscopic findings are found in CRUC (1) inflammation-predominant form (I-CRUC) with edema, mucosal pallor, and possible ulcer (2) bleeding-predominant form (B-CRUC) with friability, spontaneous hemorrhage, and telangiectasia, and (3) a mixed form with features of both I-CRUC and B-CRUC [1].

Bladder wall biopsies - especially in the previous highdose area with inflammation and necrosis - have to be avoided as they may initiate chronic, poorly healing wounds, or fistulae. The same applies for rectum biopsies [10]. Therefore, biopsies are restricted to patients with high suspicion of malignancy and in case of important therapeutic consequences. Biopsies of the lower urinary tract should always be performed in close collaborations between urologists and pelvic radiation oncologists, balancing the advantages and disadvantages of the procedure.

\section{Prevention}

Reducing the irradiated bladder and urethral volume will decrease the risk of GU toxicities by using planning constraints to optimizing the RT planning. Genetic variants and biomarkers are gaining importance in the prediction of the development of adverse effects following RT [8]. Recently, replicated genetic associations for adverse reactions to RT were reported [11]. Genetic biomarkers could help to identify high-risk on toxicity patients and that could allow radiotherapists to personalize treatments for patients for which extra care should be taken to decrease the dose to the bladder or urethra.

\section{Different RT Techniques}

The use of modern RT techniques (intensity and volumetric-modulated RT) with the use of image-guided RT and brachytherapy (internal irradiation) minimize the field and the high-dose of radiation to the bladder and urethra while maximizing the dose to the target [12]. Newer RT techniques using heavy particles like protons or carbon ions are currently being developed and tested to improve outcomes with reduced toxicities [13]. Although these methods have the potential to deliver optimal high doses of radiation to the tumor while minimizing the surrounding normal tissues, the long-term outcomes are not yet clear.

\section{Hydration}

Mild hydration and consequently diuresis are important to avoid urinary retention, with consequently possibility of infection. Moreover, it is important to achieve a clot-free bladder to avoid urinary retention.

\section{Medication}

The use of medical therapy to decrease the symptoms of RUC is described in several studies, especially with alpha-blockers, which is widely used as prophylactic therapy with brachytherapy. Merrick and coauthors [14] revealed that prophylactic alpha-blockers revealed significantly lower maximum dysuria scores: at 1-month post-brachytherapy a difference of 2.7 versus 4.2 , respectively. Elshaikh and colleagues [7] reported in a placebocontrolled phase III trial that the use of prophylactic tamsulosin showed a significant positive effect on urinary morbidity, but not on urinary retention rates.

\section{Supplements}

Cranberry (Vaccinium macrocarpon) is prophylactic measured in cystitis, and it can be prescribed in juices or capsules. Cranberry's consist of polyphenols, including flavonoids, anthocyanins, and proanthocyanidins, wellknown for their strong antioxidant properties [15]. Some previously trials revealed conflict insufficient results, however recently 2 trials were published with positive results: Bonetta and colleagues [16] reported in 370 prostate irradiated patients an incidence of 16 lower urinary tract infections $(8.7 \%)$ in the cranberry cohort $(n=184)$, while in the control group $(n=186) 45$ lower urinary tract infections $(24.2 \%)$ were recorded. Hamilton et al. [17] revealed also in prostate irradiated patients an incidence of severe cystitis in the cranberry cohort of $30 \%$ compared with those that took placebo capsules (45\%) ( $p=0.058)$; moreover, the incidence of pain and burning
Vanneste et al. 


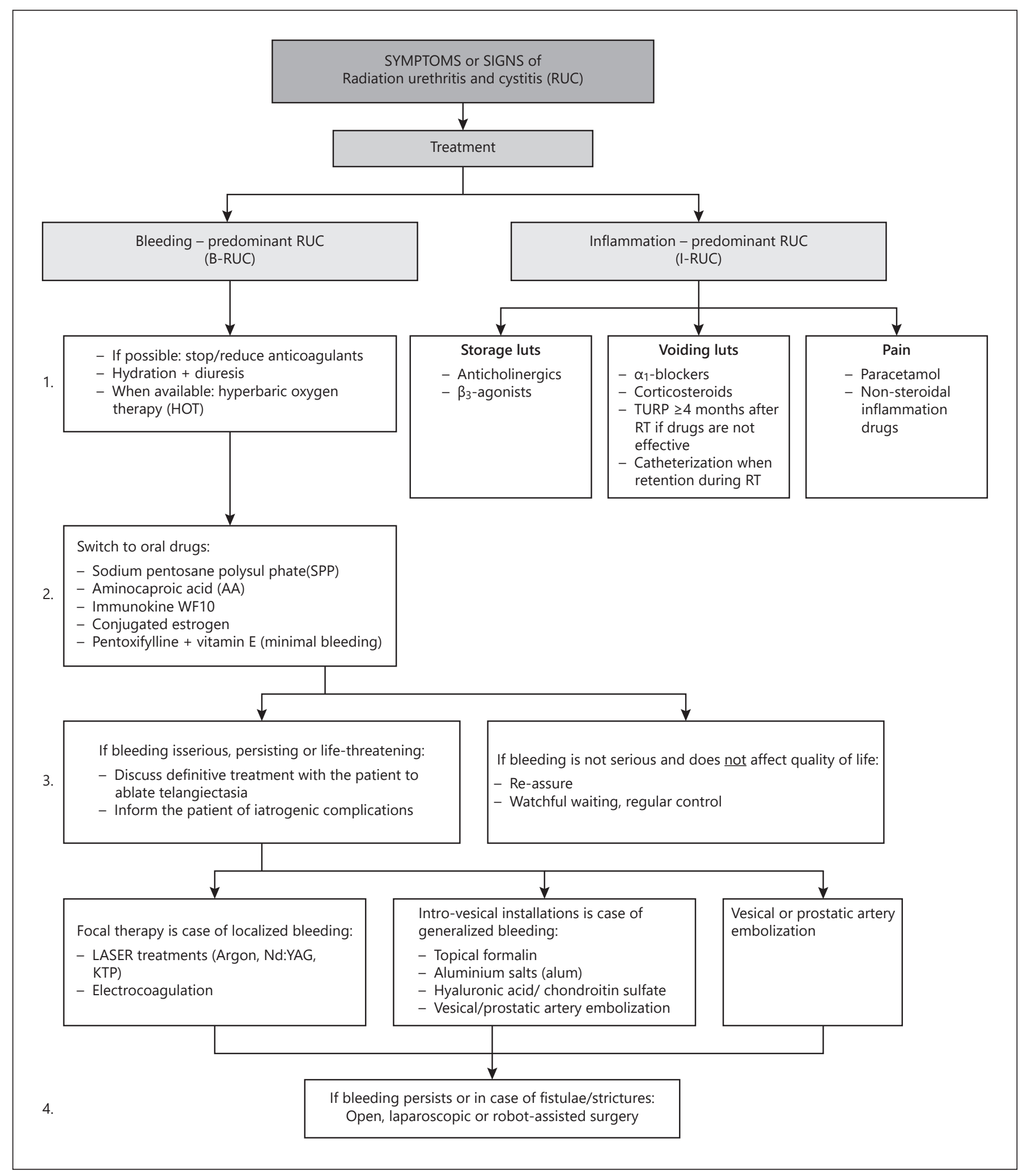

Fig. 3. Algorithm for management of RUC. RUC, radiation urethritis and cystitis.

Management Algorithm for Radiation Urethritis and Cystitis
Urol Int 2022;106:63-74

DOI: $10.1159 / 000515716$ 
was significantly lower in the cranberry cohort $(p=$ 0.045 ). However, more research is needed to confirm these results.

\section{Treatment of RUC}

Treatment of RUC has been evaluated in several studies, but no large or high-quality randomized controlled trial has been published to strengthen a particular strategy until now. Therefore, the best available evidence derives from small, mostly retrospective clinical trials, case reports, or expert opinion.

Interventions can be categorized into conservative/ medical, endoscopic, and surgical therapies. Medical therapy remains the standard treatment for both ARUC and CRUC. Nevertheless, urethro-cystoscopy should be performed if bleeding is strong, blood clots occlude the bladder outlet or urethra, malignancies of the lower urinary tract are suspected, or when patients have urinary retention or anemia. In case of urinary retention or bladder outlet obstruction, it is our opinion to avoid transurethral resection during the first 3-4 months after the RT because resection of irradiated tissue could cause chronic, poorly healing wounds and fistulae [18]. In case of bleeding, superficial coagulation of bleeding vessels is sufficient. In addition, transurethral (self) catheterization should also be omitted for the same reason, that is, creating a "false route" fistula. Before considering invasive treatments, it is essential to realize that RUC can improve over time without active treatment [18]. Donovan et al. [19] demonstrated patient-reported outcomes comparing RT with surgery or active monitoring in a well-balanced randomized phase III trial. Voiding symptoms were worse in the RT group at 6 months after treatment; however, lower urinary tract symptoms (LUTSs) returned nearly to baseline levels or were even similar to those in the active monitoring group.

In patients with CRUC, treatment should be based on the pattern and severity of symptoms. Based on the current literature, a novel treatment algorithm is suggested in Figure 3. For patients with minor symptoms or without bother, even no treatment may be indicated because CRUC has a natural history of improving over time. Donovan et al. [19] demonstrated with patient-reported outcomes that the bladder toxicities of RT (urinary voiding and nocturia) were worse in the RT group at 6 months but then mostly recovered and were similar to the other treatment groups (surgery and active monitoring) after 12 months. In case of bothersome symptoms, conservative symptomatic therapy is the cornerstone for CRUC. BCRUC is the most dramatic and frequently reported symptom and, therefore, most reports deal with this type of adverse event. Patients with B-CRUC with complaints of anemia (dyspnea upon effort, palpitations, and fatigue) should be monitored accordingly and, whenever appropriate, substituted with iron supplements or blood transfusions. Anticoagulant drugs should be reevaluated and stopped if not medically contraindicated. If the patient is hemodynamically instable, endoscopic treatment and coagulation are always indicated [4].

\section{Non-surgical Treatment for I-RUC}

Storage LUTS

Storage LUTS are often symptoms related to radiation cystitis: complaints experienced during the bladder filling and storage phase of micturition, symptoms are including urgency (incontinence), increased frequency, and nocturia. Acetylcholine receptor antagonists (anticholinergics) are effective in the treatment of storage LUTS. Anticholinergics may cause severe and bothersome adverse events, including dry mouth, constipation, post-void residual urine, or in rare cases urinary retention. However, inefficient voiding or urinary retention is rarely seen, especially when prescribed together with an $\alpha_{1}$-blocker [20]. If symptoms during RT increase, corticosteroids such as prednisone $5 \mathrm{mg}$ twice daily can be used to reduce the swelling around of the urethra in order to avoid urinary retention. In case of insufficient efficacy or side effects of anticholinergics, the new $\beta_{3}$-agonist mirabegron, although not tested for this indication, can be used for symptom relief instead [21].

\section{Voiding LUTS}

Voiding LUTS are often symptoms related to radiation urethritis: the experienced complaints are a bad, intermittent micturition, hesitancy, dysuria, and after dribbling. Voiding LUTS are more observed in men than in women and should initially be treated with $\alpha_{1}$-adrenoceptor antagonists ( $\alpha_{1}$-blockers) which reduce both bladder storage and voiding symptoms, improve urine flow and reduce postvoid residual urine. Orthostatic hypotension can often be reduced when administering $\alpha_{1}$-blockers at night before sleeping. In contrast, silodosin is a selective $\alpha_{1 \mathrm{~A}}$-adrenoceptor antagonist with no or only minor effects on blood pressure; therefore, silodosin appears to be the preferred $\alpha_{1}$ blocker in patients with (orthostatic) hypotension [22].

\section{Pain}

When pain is the predominant complaint, pain management is indicated to increase the patients' comfort level and should follow the WHO "analgesic ladder" approach to cancer pain management [23]. According to
68

Urol Int 2022;106:63-74

DOI: $10.1159 / 000515716$
Vanneste et al. 
our experience, pain originating from the lower urinary tract does not respond well to opioids, and urinary retention is a rare complication of opioids use (1\%). Moreover, bladder pain responds well to paracetamol and nonsteroidal anti-inflammatory drugs.

\section{Non-surgical Treatment for B-RUC}

Hydration and Diuresis

Mild hematuria responds very well to hydration and diuresis [5]. It is important to achieve a clot-free bladder to avoid urinary retention.

\section{Sodium Pentosane Polysulfate}

Sodium pentosane polysulfate (SPP) is an anti-inflammatory agent of which 3-5\% of the oral intake is excreted in the urine. SPP replaces the damaged glycosaminoglycan layer of the bladder (replenishing) and reverses the damage of the bladder surface [24]. In addition, the urothelium is less prone to bacterial adherence and triggers for hematuria [24]. In a retrospective nonrandomized study, Sandhu et al. [25] reported about 60 patients with hemorrhagic cystitis who were treated with oral SPP. The initial dose was $100 \mathrm{mg}$ thrice daily. The dose was reduced to a maintenance dose of $100 \mathrm{mg}$ once daily in 21 patients (35\%), and SPP could even be stopped because hematuria disappeared in 10 patients (17\%) [25]. SPP is licensed in the USA and EU for the treatment of bladder pain syndrome/interstitial cystitis $\left(\right.$ Elmiron $\left.{ }^{\circledR}\right)$.

\section{Aminocaproic Acid}

Aminocaproic acid (AA) is an antifibrinolytic agent mainly excreted into the urinary tract which counteracts the effects of urokinase that contributes to the intractability of bleeding [26]. This drug can either be administered orally, intravenously, or intravesically via catheterization and bladder irrigation.

In a retrospective nonrandomized study, Singh et al. [26] reported about 37 patients with macroscopic hematuria due to radiation cystitis, cyclophosphamide-induced cystitis, or interstitial cystitis who were treated with intravesical AA. The authors diluted $200 \mathrm{mg}$ AA per liter of physiological saline solution and continuously irrigated the bladder. This treatment was continued for $24 \mathrm{~h}$ after macroscopic hematuria diminished. Treatment resulted in 34 responders (92\%). However, catheterization and intravesical instillation were used in this case series.

\section{Immunokine WF10}

Immunokine WF10 inhibits inflammation associated with submucosal endarteritis [27]. Veerasarn et al.
[27] demonstrated in a randomized, multicenter phase II trial in 100 patients that oral WF10 therapy is a safe and effective treatment. WF10, also known as Tetrachloro-deca-oxygen (TCDO), was administered in a dose of $0.5 \mathrm{~mL} / \mathrm{kg}$ bodyweight, diluted in $250 \mathrm{~mL}$ physiological saline solution, and infused intravenously for $2 \mathrm{~h}$. Infusions were repeated for 5 days per week every 3 weeks for 2 cycles plus standard treatment (WF10 group) or standard treatment alone (control group). The standard treatment consisted of oral antibiotics, antispasmodics, iron supplement, blood transfusions, continuous bladder irrigation with physiological saline solution, and evacuation of blood clots from the bladder, if necessary. At week 7, a total of 37 patients of the WF10 group $(74 \%)$ and 32 control patients $(64 \%)$ stopped bleeding $(p=0.28)$.

\section{Conjugated Estrogen}

Estrogens decrease vascular fragility associated with hemorrhage late radiation cystitis. Liu et al. [28] reported about a significant improvement of hematuria in $4 / 5 \mathrm{pa}-$ tients following estrogen therapy $5 \mathrm{mg}$ once daily.

\section{Pentoxifylline}

Pentoxifylline downregulates different pro-inflammatory cytokines and has an antioxidant effect [29]. This mechanism of action can potentially avoid late radiation toxicity. Randomized, placebo-controlled trials of combined pentoxifylline in combination with tocopherol (vitamin E) have a confirmed efficacy for regression of superficial radiation-induced fibrosis in other sites like skin, head, and neck mucosa [30].

\section{Hyperbaric Oxygen Therapy}

HOT is the only well-examined approach in the literature for treating B-CRUC. Unfortunately, HOT facilities are rare in some countries. Other limitations of HOT treatment are the costs and time-consuming treatment (60-120 min for 30-70 sessions). Patients with HOT breathe pure oxygen (100\%) in a closed room in which the air pressure is increased to $2-3$ times of the normal air pressure [31]. Consequently, the lungs can absorb more oxygen than with normal air pressure. The rationale is that highly oxygenated blood seems to be beneficial because it inhibits bacterial growth, increases angiogenesis, and stimulates the release of growth factors and stem cells, which all promote wound healing. It may even reverse progressive changes caused by RT and may improve other related symptoms such as radiation proctitis [31]. A Cochrane review based on 14 randomized controlled 
Table 2. Summary of trials treating hemorrhagic cystitis with HOT [33, 35-46]

\begin{tabular}{|c|c|c|c|c|}
\hline Lee et al. [36] & 1994 & Retrospective & 20 & 90 \\
\hline Bevers et al. [37] & 1995 & Prospective & 50 & 92 \\
\hline Chong et al. [38] & 2005 & Retrospective & 60 & 80 \\
\hline Vilar et al. [39] & 2011 & Prospective & 38 & 90 \\
\hline Oliai et al. [35] & 2012 & Retrospective & 11 & 90 \\
\hline Nakada et al. [41] & 2012 & Retrospective & 38 & 74 \\
\hline Oscarsson et al. [42] & 2013 & Prospective & 39 & 76 \\
\hline Shilo et al. [43] & 2013 & Retrospective & 32 & 84 \\
\hline Tahir et al. [44] & 2015 & Retrospective & 20 & 84 \\
\hline Mougin et al. [45] & 2016 & Retrospective & 71 & 65 \\
\hline Dellis et al. [46] & 2017 & Prospective & 36 & 100 \\
\hline
\end{tabular}

HOT, hyperbaric oxygen therapy.

trials demonstrated a benefit of HOT in preventing or healing late RT toxicity [32]. Bennett et al. [32] suggested that for patients with late RT toxicity affecting tissues of the head, neck, anus, and rectum, HOT is associated with improved clinical outcome.

Several retro- and prospective studies on HOT have been published showing an overall success rate in 65$100 \%$ of patients (Table 2). The RICH-ART study is a phase II-III randomized trial, which reported that HOT relieves symptoms of late radiation cystitis: an improvement of 10.1 points of the Expanded Prostate Index Composite urinary score were observed in favor of HOT [33]. Villeirs et al. [34] conducted a systematic review on the use of HOT in RUC: they concluded that HOT is effective, with minimal adverse events, however with low access and high costs.

\section{Interventional Treatment of RUC \\ Catheterization}

The bladder needs to be drained by transurethral or suprapubic catheterization when patients develop urinary retention during RT. Transurethral catheterization should be done with caution because the whole urethra can be irritated and the urethral wall may be fragile. Therefore, transurethral catheterization should be performed by experienced physicians in these patients. If catheterization is needed for a longer period, suprapubic catheterization is the preferred method [52]. Suprapubic catheterization also has the advantage that the patient can measure post-void residual urine after RT and before catheter removal.
Intravesical Instillations, Endoscopic Treatments, and Surgery for B-RUC

A variety of intravesical and cystoscopic therapies are available for B-CRUC. Instillation therapies for B-RUC should only be considered after failure of oral (drug) therapies [35]. Due to the known potential risk of fistulae, ulcerations, or urethral stenoses, we advise that all cystoscopic treatments should be performed by an experienced urologist.

\section{Intravesical Instillations}

Formalin

Formalin occludes and fixes fragile neovasculature in RT-damaged tissues through chemical cauterization [53]. The success rate of this technique ranges from 75 to $89 \%$ [53]. Despite the high success rate, this treatment is potentially associated with major complications in up to $33 \%$ of patients, including fistulae (vesicovaginal and vesicointestinal), necrosis, ulcerations, fibrosis, obstruction, bilateral hydronephrosis, and decreased bladder capacity requiring urinary diversion [53]. It is important to check the different formalin concentrations which range from 1 to $10 \%$ [53]. A retrospective study showed that $1 \%$ formalin was equally effective compared to the 2 or $4 \%$ solution with regard to hemostasis but caused fewer side effects (need of urinary diversion and persistent bleeding) [53].

Aluminum Salts

Aluminum salts (alum) trigger vasoconstriction and decrease capillary permeability which stops bleeding in 
Table 3. Summary of trials treating hemorrhagic cystitis with endoscopic treatments [47-51]

\begin{tabular}{|c|c|c|c|c|c|}
\hline First author & $\begin{array}{l}\text { Year } \\
\text { published }\end{array}$ & Design & Modality & $\begin{array}{l}\text { Patients, } \\
n\end{array}$ & $\begin{array}{l}\text { Success rate (\%) } \\
\text { (complete and partial) }\end{array}$ \\
\hline Ravi et al. [47] & 1994 & Prospective & YAG laser & 42 & 93 \\
\hline Wines et al. [51] & 2006 & Retrospective & APC & 7 & 65 \\
\hline Zhu et al. [49] & 2013 & Retrospective & KTP laser & 10 & 100 \\
\hline Talab et al. [48] & 2014 & Retrospective & KTP laser & 20 & 90 \\
\hline Martinez et al. [50] & 2015 & Retrospective & KTP laser & 4 & 100 \\
\hline
\end{tabular}

APC, argon plasma coagulation.

mild cases [54]. Westerman et al. [54] reported in a retrospective series that $24 / 40$ patients $(60 \%)$ needed no additional therapy after intravesical alum installations [54]. Alum should be cautiously instilled because patients may develop acute alum toxicity leading to renal insufficiency and neurotoxicity [55].

Hyaluronic Acid and Chondroitin Sulfate

Hyaluronic acid and chondroitin sulfate represent replenishment therapies [56]. Shao et al. [56] compared intravesical hyaluronic acid instillation with hyperbaric oxygen in a series of 36 patients. No significant differences between the treatment groups were seen in terms of efficacy at 12 months; the response was $85 \%$ ( 17 out of 20 ) patients treated with HOT compared with $94 \%$ (15 out of 16) in the hyaluronic acid group.

\section{Prostaglandins}

Prostaglandins induce vasoconstriction and stimulate muscle contractions in blood vessels in the mucosa and submucosa of the bladder, thereby reducing edema and the inflammatory response [34]. A similar response is observed in the uterus when prostaglandins are used for therapeutic abortion and refractory postpartum uterine bleeding [57]. However, only small case studies have been published demonstrating only small benefits in treatment of B-CRUC [57-59]. The authors feel that data on prostaglandins is insufficient in patients after RT and, therefore, do not recommend this treatment.

\section{Endoscopic Treatments}

Laser and Argon Plasma Coagulation

The argon, neodymium/yttrium aluminum garnet (Nd:YAG) and potassium titanyl phosphate (KTP) lasers have been used to coagulate bleeding vessels in the lower urinary tract (Table 3) [47-51]. Some retro- and prospective studies have been published; however, data are still scare. All studies did not have a control arm (sham treatment) and did not take into account that CRUC can improve over time without treatment. Argon plasma coagulation (APC) is a form of electrocautery in which monopolar diathermy is transmitted to the target tissue through an ionized gas in a noncontact fashion $(0.8-3.0 \mathrm{~mm}$ distance from the target) [1]. APC is well known and broadly used by gastroenterologists for the treatment of radiation proctitis [1]. APC seems to be a promising but still preliminary treatment option.

\section{Vesical Artery Embolization}

Minimal invasive treatment option is vesical artery embolization. Alternatively, surgical ligation of iliac arteries can also be performed [60]. Vesical artery embolization by skilled and experienced interventional radiologists is a minimal invasive therapy with potentially less complications [60]. The technique has been first described by Pisco et al. for treating benign prostate enlargement with severe LUTS otherwise mandating surgery [61]. However, it is also a very effective treatment for recurrent and intractable bleeding [62-65] Due to the minimal invasive nature, embolization is well endured by patients even with comorbidities or after previous extensive surgery or RT. Therefore, we recommend considering vesical artery embolization for patients with (recurrent) bleeding after surgical intervention or RT as a less invasive alternative for surgical management.

\section{Surgery}

Surgery is considered as the last resort for patients with B-CRUC after failure of all other treatments. Surgery should be reserved for patients who have permanent, potentially life-threatening bleeding or fistulae which do not respond to conservative or endoscopic 
treatments [65]. Surgical treatment options range from cutaneous urinary diversion to urinary diversion such as ileal or colon loop diversion, with or without a cystectomy [66]. The goal of supravesical diversion is to decrease the exposure of the hemorrhagic areas to urokinase to allow hemostasis [5]. Urinary diversion should not include the irradiated area.

All surgical procedures, especially major surgery inside the irradiated pelvis, are associated with high morbidity and mortality [65]. Linder et al. [66] observed severe (grade III to V) complications in $8 / 19$ patients (42\%) and reported about a 90 -day mortality rate in $3 / 19$ patients (16\%). Sack et al. [67] demonstrated in a series of 15 patients that cystectomy with urinary diversion can improve quality of life. However, in 4 patients (27\%) early complications occurred, such as deep wound infections, abdominal wall dehiscence, bowel leak, and colitis caused by Clostridium difficile. In 7 patients (47\%), late complications were observed such as incisional hernia, pelvic abscess, entero-cutaneous fistula, parastomal hernia, and uretero-enteric stricture.

Al Hussein et al. [68] reported about robot-assisted cystectomy in 46 patients with a history of pelvic RT. The reasons for cystectomy were secondary bladder and prostate cancer in $30(65 \%)$ and 2 patients (2\%), respectively. Complications following surgery included fistulae and intractable symptoms (mainly continuous hematuria) in 5 (11\%) and 9 patients (20\%), respectively. The authors saw complications during the first 90 days after surgery in $25(54 \%)$ patients of whom 11 (24\%) had major complications and $1(2 \%)$ patient even died. Infections, bleeding, and gastrointestinal complications were the most common adverse events. Important to mention is that difficult cases with a history of pelvic RT were more likely to undergo an open procedure, which may have resulted in a selection bias with an overestimation (open surgery) or underestimation (robot-assisted surgery) of complications.

\section{Limitations}

The presented algorithm has some limitations. It is based on small, low-level, and often historical trials. Therefore, a meta-analysis was not possible. In the literature, no general consensus has been reached until now. More prospective research is recommended to increase the knowledge of both prevention and treatment of CRUC. Furthermore, the provided algorithm reflects expert opinion.

\section{Conclusions}

RUC is a frequently observed late adverse event of pelvic $\mathrm{RT}$ and can occur even years after treatment. The risk of RUC should be minimized by applying improved RT techniques such as intensity-modulated RT, image-guided RT, or brachytherapy. Diagnosis of RT-associated symptoms and signs are primarily done by exclusion of other potential causes. On the basis of the available literature, we constructed a practical 4-step management algorithm for the whole spectrum of RUC (Fig. 3). Nevertheless, prospective controlled and larger studies are recommended to increase the knowledge of both prevention and treatment of RUC.

\section{Statement of Ethics}

As the corresponding author, I declare that the work described in the manuscript is unpublished and is not concurrently being considered for publication elsewhere. I can confirm that the manuscript has been read and approved by all named authors and that there are no other persons who satisfied the criteria for authorship but are not listed. I further confirm that the order of authors listed in the manuscript has been approved by all of us. No informed consent is required. The authors declare no disclosures of potential conflicts of interest. Research involving human participants and/or animals: none. No informed consent is required.

\section{Conflict of Interest Statement} terest.

The authors declare no disclosures of potential conflicts of in-

\section{Funding Sources}

No funding relevant to the study.

\section{Author Contribution}

B. Vanneste: project development, data collection, manuscript writing; E. Van Limbergen: project development, manuscript writing; T. Marcelissen: manuscript writing; J. Van Roermund: manuscript writing; L. Lutgens: manuscript writing; C. Arnoldussen: manuscript writing; P. Lambin: manuscript writing; Matthias Oelke: project development, data collection, and manuscript writing.
72

Urol Int 2022;106:63-74

DOI: $10.1159 / 000515716$
Vanneste et al. 


\section{References}

1 Vanneste BG, Van De Voorde L, de Ridder RJ, Van Limbergen EJ, Lambin P, van Lin EN. Chronic radiation proctitis: tricks to prevent and treat. Int J Colorectal Dis. 2015;30(10): 1293-303.

2 Smit SG, Heyns CF. Management of radiation cystitis. Nat Rev Urol. 2010;7(4):206-14.

3 Dörr W, Hendry JH. Consequential late effects in normal tissues. Radiother Oncol. 2001;61(3):223-31.

4 Mallick S, Madan R, Julka PK, Rath GK. Radiation induced cystitis and proctitis - prediction, assessment and management. Asian Pac J Cancer Prev. 2015;16(14):5589-94.

5 Browne C, Davis NF, Mac Craith E, Lennon GM, Mulvin DW, Quinlan DM, et al. A narrative review on the pathophysiology and management for radiation cystitis. Adv Urol. 2015;2015:346812.

6 Common Terminology Criteria for Adverse Events 4.0 (CTCAE) (http://ctep.cancer.gov/ protocol Development/electronic_applications/ctc.htm).

7 Elshaikh MA, Ulchaker JC, Reddy CA, Angermeier KW, Klein EA, Chehade N, et al. Prophylactic tamsulosin (Flomax) in patients undergoing prostate 125I brachytherapy for prostate carcinoma: final report of a doubleblind placebo-controlled randomized study. Int J Radiat Oncol Biol Phys. 2005;62(1): 164.

8 Seibold P, Webb A, Aguado-Barrera ME, Azria $\mathrm{D}$, Bourgier $\mathrm{C}$, Brengues $\mathrm{M}$, et al. REQUITE consortium (2019). REQUITE: a prospective multicentre cohort study of patients undergoing radiotherapy for breast, lung or prostate cancer. Radiother Oncol. 2019;138: 59-67.

9 Porru D, Jallous H, Cavalli V, Sallusto F, Rovereto B. Prognostic value of a combination of IPSS, flow rate and residual urine volume compared to pressure-flow studies in the preoperative evaluation of symptomatic $\mathrm{BPH}$. Eur Urol. 2002;41(3):246-9.

10 Chrouser KL, Leibovich BC, Sweat SD, Larson DW, Davis BJ, Tran NV, et al. Urinary fistulas following external radiation or permanent brachytherapy for the treatment of prostate cancer. J Urol. 2005;173(6):1953-7.

11 Massi MC, Gasperoni F, Ieva F, Paganoni AM, Zunino P, Manzoni A, et al. A deep learning approach validates genetic risk factors for late toxicity after prostate cancer radiotherapy in a REQUITE multi-national cohort. Front Oncol. 2020;10:541281.

12 Pieters BR, van der Steen-Banasik E, Smits GA, De Brabandere M, Bossi A, Van Limbergen E. GEC-ESTRO/ACROP recommendations for performing bladder-sparing treatment with brachytherapy for muscle-invasive bladder carcinoma. Radiother Oncol. 2017; 122(3):340-6

13 Takaoka EI, Miyazaki J, Ishikawa H, Kawai K, Kimura T, Ishitsuka R, et al. Long-term single-institute experience with trimodal bladder-preserving therapy with proton beam therapy for muscle-invasive bladder cancer. Jpn J Clin Oncol. 2017;47(1):67-73.

14 Merrick GS, Butler WM, Wallner KE, Allen ZA, Galbreath RW, Lief JH, et al. The impact of radiation dose to the urethra on brachytherapy-related dysuria. Brachytherapy. 2005;4(1):45-50.

15 Côté J, Caillet S, Doyon G, Sylvain JF, Lacroix $\mathrm{M}$. Bioactive compounds in cranberries and their biological properties. Crit Rev Food Sci Nutr. 2010;50(7):666-79.

16 Bonetta A, Di Pierro F. Enteric-coated, highly standardized cranberry extract reduces risk of UTIs and urinary symptoms during radiotherapy for prostate carcinoma. Cancer Manag Res. 2012;4:281-6.

17 Hamilton K, Bennett NC, Purdie G, Herst PM. Standardized cranberry capsules for radiation cystitis in prostate cancer patients in New Zealand: a randomized double blinded, placebo controlled pilot study. Support Care Cancer. 2015;23(1):95-102.

18 Ishiyama $\mathrm{H}$, Hirayama $\mathrm{T}$, Jhaveri $\mathrm{P}$, Satoh $\mathrm{T}$, Paulino AC, $\mathrm{Xu} \mathrm{B}$, et al. Is there an increase in genitourinary toxicity in patients treated with transurethral resection of the prostate and radiotherapy? A systematic review. Am J Clin Oncol. 2014;37(3):297-304.

19 Donovan JL, Hamdy FC, Lane JA, Mason M, Metcalfe C, Walsh E, et al. Patient-reported outcomes after monitoring, surgery, or radiotherapy for prostate cancer. N Engl J Med. 2016;375(15):1425-37.

20 Oelke M, Bachmann A, Descazeaud A, Emberton M, Gravas S, Michel MC, et al. EAU guidelines on the treatment and follow-up of non-neurogenic male lower urinary tract symptoms including benign prostatic obstruction. Eur Urol. 2013;64(1):118-40.

21 Kelleher C, Hakimi Z, Zur R, Siddiqui E, Maman K, Aballéa S, et al. Efficacy and tolerability of mirabegron compared with antimuscarinic monotherapy or combination therapies for overactive bladder: a systematic review and network meta-analysis. Eur Urol. 2018; 74(3):324-33

22 Oelke M, Gericke A, Michel MC. Cardiovascular and ocular safety of a1-adrenoceptor antagonists in the treatment of male lower urinary tract symptoms. Expert Opin Drug Saf. 2014;13(9):1187-97.

23 World Health Organization. Cancer pain relief. Geneva: World Health Organization; 1990.

24 Parsons CL, Forrest J, Nickel JC, Evans R, Lloyd LK, Barkin J, et al. Effect of pentosan polysulfate therapy on intravesical potassium sensitivity. Urology. 2002;59(3):329-33.

25 Sandhu SS, Goldstraw M, Woodhouse CR. The management of haemorrhagic cystitis with sodium pentosan polysulphate. BJU Int. 2004;94(6):845-7.

26 Singh I, Laungani GB. Intravesical epsilon aminocaproic acid in management of intractable bladder hemorrhage. Urology. 1992; 40(3):227-9.
27 Veerasarn V, Boonnuch W, Kakanaporn C. A phase II study to evaluate WF10 in patients with late hemorrhagic radiation cystitis and proctitis. Gynecol Oncol. 2006;100(1):17984.

28 Liu YK, Harty JI, Steinbock GS, Holt HA, Goldstein DH, Amin M. Treatment of radiation or cyclophosphamide induced hemorrhagic cystitis using conjugated estrogen. J Urol. 1990;144(1):41-3.

29 Freitas JP, Filipe PM, Pentoxifylline . Pentoxifylline. A hydroxyl radical scavenger. Biol Trace Elem Res. 1995;47(1-3):307-11.

30 Patel V, McGurk M. Use of pentoxifylline and tocopherol in radiation-induced fibrosis and fibroatrophy. Br J Oral Maxillofac Surg. 2017; 55(3):235-41.

31 Feldmeier JJ, Hampson NB. A systematic review of the literature reporting the application of hyperbaric oxygen prevention and treatment of delayed radiation injuries: an evidence based approach. Undersea Hyperb Med. 2002;29(1):4-30.

32 Bennett $\mathrm{MH}$, Feldmeier J, Hampson NB, Smee R, Milross C. Hyperbaric oxygen therapy for late radiation tissue injury. Cochrane Database Syst Rev. 2016;4:CD005005.

33 Oscarsson N, Müller B, Rosén A, Lodding P, Mölne J, Giglio D, et al. Radiation-induced cystitis treated with hyperbaric oxygen therapy (RICH-ART): a randomised, controlled, phase 2-3 trial. Lancet Oncol. 2019;20(11): 1602-14.

34 Villeirs L, Tailly T, Ost P, Waterloos M, Decaestecker K, Fonteyne V, et al. Lumen $\mathrm{N}$ hyperbaric oxygen therapy for radiation cystitis after pelvic radiotherapy: systematic review of the recent literature. Int J Urol. 2020 Feb; 27(2):98-107.

35 Oliai C, Fisher B, Jani A, Wong M, Poli J, Brady LW, et al. Hyperbaric oxygen therapy for radiation-induced cystitis and proctitis. Int J Radiat Oncol Biol Phys. 2012;84(3):73340.

36 Lee HC, Liu CS, Chiao C, Lin SN. Hyperbaric oxygen therapy in hemorrhagic radiation cystitis: a report of 20 cases. Undersea Hyperb Med. 1994;21(3):321-7.

37 Bevers RF, Bakker DJ, Kurth KH. Hyperbaric oxygen treatment for haemorrhagic radiation cystitis. Lancet. 1995;346(8978):803-5.

38 Chong KT, Hampson NB, Corman JM. Early hyperbaric oxygen therapy improves outcome for radiation-induced hemorrhagic cystitis. Urology. 2005;65(4):649-53.

39 Vilar DG, Fadrique GG, Martín IJ, Aguado JM, Perelló CG, Argente VG, et al. Hyperbaric oxygen therapy for the management of hemorrhagic radio-induced cystitis. Arch Esp Urol. 2011;64(9):869-74.

40 Hampson NB, Holm JR, Wreford-Brown CE, Feldmeier J. Prospective assessment of outcomes in 411 patients treated with hyperbaric oxygen for chronic radiation tissue injury. Cancer. 2012;118(15):3860-8 
41 Nakada T, Nakada H, Yoshida Y, Nakashima Y, Banya Y, Fujihira T, et al. Hyperbaric oxygen therapy for radiation cystitis in patients with prostate cancer: a long-term follow-up study. Urol Int. 2012;89(2):208-14.

42 Oscarsson N, Arnell P, Lodding P, Ricksten SE, Seeman-Lodding H. Hyperbaric oxygen treatment in radiation-induced cystitis and proctitis: a prospective cohort study on patient-perceived quality of recovery. Int $\mathrm{J}$ Radiat Oncol Biol Phys. 2013;87(4):670-5.

43 Shilo Y, Efrati S, Simon Z, Sella A, Gez E, Fenig E, et al. Hyperbaric oxygen therapy for hemorrhagic radiation cystitis. Isr Med Assoc J. 2013;15(2):75-8.

44 Tahir AR, Westhuyzen J, Dass J, Collins MK, Webb R, Hewitt S, et al. Hyperbaric oxygen therapy for chronic radiation-induced tissue injuries: Australasia's largest study. Asia Pac J Clin Oncol. 2015;11(1):68-77.

45 Mougin J, Souday V, Martin F, Azzouzi AR, Bigot P. Evaluation of hyperbaric oxygen therapy in the treatment of radiation-induced hemorrhagic cystitis. Urology. 2016;94:42-6.

46 Dellis A, Papatsoris A, Kalentzos V, Deliveliotis C, Skolarikos A. Hyberbaric oxygen as sole treatment for severe radiation - induced haemorrhagic cystitis. Int Braz J Urol. 2017; 43(3):489-95.

47 Ravi R. Endoscopic neodymium: YAG laser treatment of radiation-induced hemorrhagic cystitis. Lasers Surg Med. 1994;14(1):83-7.

48 Talab SS, McDougal WS, Wu CL, Tabatabaei S. Mucosa-sparing, KTP laser coagulation of submucosal telangiectatic vessels in patients with radiation-induced cystitis: a novel approach. Urology. 2014;84(2):478-83.

49 Zhu J, Xue B, Shan Y, Yang D, Zang Y. Transurethral coagulation for radiation-induced hemorrhagic cystitis using Greenlight ${ }^{\text {tim }}$ potassium-titanyl-phosphate laser. Photomed Laser Surg. 2013;31(2):78-81.

50 Martinez DR, Ercole CE, Lopez JG, Parker J, Hall MK. A Novel approach for the treatment of radiation-induced hemorrhagic cystitis with the GreenLightTM XPS laser. Int Braz J Urol. 2015;41(3):584-7.
51 Wines MP, Lynch WD. A new minimally in vasive technique for treating radiation cystitis: the argon-beam coagulator. BJU Int. 2006; 98(3):610-2.

52 Horgan AF, Prasad B, Waldron DJ, O'Sullivan DC. Acute urinary retention. Comparison of suprapubic and urethral catheterisation. Br J Urol. 1992;70(2):149-51.

53 Lojanapiwat B, Sripralakrit S, Soonthornphan S, Wudhikarn S. Intravesicle formalin instillation with a modified technique for controlling haemorrhage secondary to radiation cystitis. Asian J Surg. 2002;25(3):232-5.

54 Westerman ME, Boorjian SA, Linder BJ. Safety and efficacy of intravesical alum for intractable hemorrhagic cystitis: a contemporary evaluation. Int Braz J Urol. 2016;42(6): 1144-9.

55 Perazella M, Brown E. Acute aluminum toxicity and alum bladder irrigation in patients with renal failure. Am J Kidney Dis. 1993; 21(1):44-6.

56 Shao Y, Lu GL, Shen ZJ. Comparison of intravesical hyaluronic acid instillation and hyperbaric oxygen in the treatment of radiationinduced hemorrhagic cystitis. BJU Int. 2012; 109(5):691-4.

57 Levine LA, Kranc DM. Evaluation of carboprost tromethamine in the treatment of cyclophosphamide-induced hemorrhagic cystitis. Cancer. 1990;66(2):242-5.

58 Miura M, Sasagawa I, Kubota Y, Iijima Y, Sawamura T, Nakada T. Effective hyperbaric oxygenation with prostaglandin E1 for radiation cystitis and colitis after pelvic radiotherapy. Int Urol Nephrol. 1996;28(5):643-7.

59 Hemal AK, Vaidyanathan S, Sankaranarayanan A, Ayyagari S, Sharma PL. Control of massive vesical hemorrhage due to radiation cystitis with intravesical instillation of $15(\mathrm{~s})$ 15-methyl prostaglandin F2-alpha. Int J Clin Pharmacol Ther Toxicol. 1988;26(10):477-8.
60 Rezaeimehr B, Modanloo M, Davoodi M, Sakhaei SM, Farsavian H, Younesi Rostami M. Angioemboliziation of internal pudendal artery for treatment of long lasting gross hematuria after transurethral resection of the prostate. Urol J. 2019;16(5):517-8.

61 Pisco JM, Pinheiro LC, Bilhim T, Duarte M, Mendes JR, Oliveira AG. Prostatic arterial embolization to treat benign prostatic hyperplasia. J Vasc Interv Radiol. 2011;22(1):11-20.

62 Tapping CR, Macdonald A, Hadi M, Mortensen C, Crew J, Protheroe A, et al. Prostatic artery embolization (PAE) for benign prostatic hyperplasia $(\mathrm{BPH})$ with haematuria in the absence of an upper urinary tract pathology. Cardiovasc Intervent Radiol. 2018; 41(8):1160-4.

63 Bonne L, Gillardin P, De Wever L, Vanhoutte E, Joniau S, Oyen R, et al. Endovascular management of severe arterial haemorrhage after radical prostatectomy: a case series. Cardiovasc Intervent Radiol. 2017;40(11):1698-705.

64 Comploj E, Pycha A, Trenti E, Palermo S, Bonatti M, Krause $\mathrm{P}$, et al. Transarterial embolization in the management of intractable haemorrhage. Urol Int. 2020 Oct 16:1-5.

65 De Berardinis E, Vicini P, Salvatori F, Sciarra A, Gentile V, Di Silverio F. Superselective embolization of bladder arteries in the treatment of intractable bladder haemorrhage. Int $\mathrm{J}$ Urol. 2005;12(5):503-5.

66 Linder BJ, Tarrell RF, Boorjian SA. Cystectomy for refractory hemorrhagic cystitis: contemporary etiology, presentation and outcomes. J Urol. 2014;192(6):1687-92.

67 Sack BS, Langenstroer P, Guralnick ML, Jacobsohn KM, O'Connor RC. Cystectomy and urinary diversion for the management of a devastated lower urinary tract following prostatic cryotherapy and/or radiotherapy. WMJ. 2016;115(2):70-3.

$68 \mathrm{Al}$ Hussein Al Awamlh B, Nguyen DP, Otto B, O'Malley P, Khan F, Brooks S, et al. The safety of robot-assisted cystectomy in patients with previous history of pelvic irradiation. BJU Int. 2016 Sep;118(3):437-43. 